\title{
Natural Suitability Evaluation of Habitat Environment in Transition Zone Based on GIS Spatial Analysis Technology-Taking Beichuan County as an Example
}

\author{
Tao Liu \\ School of Civil Engineering and Architecture, Southwest University of Science and Technology, Mianyang, China \\ Email: liutaoazl@163.com
}

How to cite this paper: Liu, T. (2021). Natural Suitability Evaluation of Habitat Environment in Transition Zone Based on GIS Spatial Analysis Technology-Taking Beichuan County as an Example. Journal of Geoscience and Environment Protection, 9, 151-162.

https://doi.org/10.4236/gep.2021.98010

Received: July 12, 2021

Accepted: August 17, 2021

Published: August 20, 2021

Copyright $\odot 2021$ by author(s) and Scientific Research Publishing Inc. This work is licensed under the Creative Commons Attribution International License (CC BY 4.0).

http://creativecommons.org/licenses/by/4.0/

\begin{abstract}
Analyzing and measuring the spatial distribution pattern of human settlement environment suitability in Beichuan County China is of great significance for optimizing population distribution and promoting human development and environmental protection. Based on the DEM data and other data of Beichuan County, this paper uses GIS and ENVI software to extract four spatial distribution data of vegetation coverage index, topographic relief, hydrological index and natural disaster risk, and the spatial distribution pattern of natural suitability of human settlement environment in Beichuan County was obtained through overlay analysis. The results show: 1) Most of the areas with small topographic relief are located in the southeast of the study area, which is New Beichuan County and Anchang Town and Yong'an Town. The vegetation coverage index in the eastern region is higher, while the vegetation coverage index in the western and other high altitude regions is lower because there are more grasslands. 2) From the perspective of spatial distribution, Beichuan County as a whole is rich in water resources in the central and eastern part of the county, while the west is short of water resources; Chenjiaba Township, Guixi Town and Old Beichuan County are located on the fault zone with high natural disaster risk, the natural disaster risk is high in Piankou Township and Xiaoba Town and Kaiping Township Area. 3) The human settlement environment index of Beichuan county is 19.72 - 85.25; The natural suitability is the highest in the southeast, followed by the central and western regions, and the worst is located in the Piankou-Xiaoba and Old Beichuan-Guixi fault zones. 4) The general suitable area in Beichuan County is the largest, accounting for $30.4 \%$ of the total area of the study area. More suitable area ranked second, accounting for $29.33 \%$; critical fitness suitable
\end{abstract}


area accounted for $17.87 \%$; the area of suitable highly suitable area accounted for $14.06 \%$, and the unsuitable area accounted for $8.32 \%$. Reasonable and efficient development and use of local resources is an inevitable way for the sustainable development of Beichuan County.

\section{Keywords}

Habitat Environment, Spatial Pattern, GIS, Beichuan County

\section{Introduction}

Human settlement environment is the organic synthesis of material and immaterial required by human activities, and it is also the main battlefield of human life and production. Its unique position has attracted more scholars' and experts' attention and attention (Yang et al., 2013). Scholar Wu Liangyong highly summarized the human settlement environment into five systems, namely: natural system, human system, social system, residential system, and support system (Mao, 2019), later, scholars took different perspectives in different fields as the entry point to study these five systems. Most geographers focus on two aspects of their research on human settlement environment. One is to explore the impact of natural environment on human life and production based on natural system and starting from a number of natural elements (Ma et al., 2014); the other is to explore the natural environment and ecology as the main human settlement environment in a specific region, such as the administrative area river basin (Wang, 2020). The report of the 19th National Congress of the Communist Party of China on the establishment and improvement of the overall planning of the land and space of cities and counties proposes to carry out "double evaluation" work, of which the evaluation of natural resource carrying capacity is the basic work for human survival and development (Feng et al., 2017). However, for the dynamic and complex natural environment, it is difficult to establish the evaluation model of natural resource carrying capacity involving all aspects of the ecological environment (Zhao et al., 2019), By evaluating the suitability of regional natural resources and environment and establishing the model, it can help to reveal the carrying capacity of natural resources and environment, and play a positive effect on the coordinated development of regional "human-land-environment" (Xu et al., 2016). The research on the natural suitability of human settlement environment is transitioning from the national and provincial large-scale space research (Zhu, 2013). The research is transitioned into small scale space at the city level and county level (Ayinur, 2012), its core point is small-scale research can better match with regional territorial spatial planning, and at the same time, the accuracy and accuracy of analysis have been greatly improved, so it has certain practicability and reference significance (Zhang et al., 2012).

Beichuan Qiang Autonomous County is located in the mountainous transitional zone of western Sichuan, its unique geographical environment created a 
complex residential space environment, since the 5.12 Wenchuan earthquake, Beichuan has high-speed economic development, but its living space environment development uncoordinated, landslides mudslides, and floods and other natural disasters frequently occur, it has a non-negligible impact on regional human production and life. Based on this situation, taking Beichuan County of Mianyang City as an example, combining the specific conditions of the study area, this paper discusses the spatial pattern of the natural suitability of the human settlement environment in Beichuan County from the four spatial distribution data of vegetation coverage index, topographic relief, hydrological index, and natural disaster risk. That provided reference for the delineation of "double evaluation" in Beichuan County and the coordinated development of local environment and production.

\section{Introduction to the Study Area}

Beichuan County, located in the northwest of Sichuan Basin, is the junction of Chengdu Plain and Northwest Sichuan Plateau (Figure 1). Located in $103^{\circ} 44^{\prime} \mathrm{E}$ $104^{\circ} 42^{\prime} \mathrm{E}$, latitude $31^{\circ} 14^{\prime} \mathrm{N}-32^{\circ} 14^{\prime} \mathrm{N}$, it is adjacent to Jiangyou City in the east, Anzhou District in the south, Mao County in the west, Pingwu County and Songpan County in the north, 42 kilometers away from downtown Mianyang City and 160 kilometers away from the provincial capital Chengdu. The administrative area of Beichuan County covers an area of $2867.83 \mathrm{~km}$, with a permanent population of 220,600 (in 2019). The highest elevation is $4769 \mathrm{~m}$, the lowest is $540 \mathrm{~m}$, and the largest relative height difference is $4229 \mathrm{~m}$. Longmen Mountain fold belt and Houlongmen Mountain fold belt all pass through this area.

\section{Data Sources and Research Methods}

\subsection{Data Sources}

DEM data comes from ASTER GDEM 30 m resolution image of Geographic

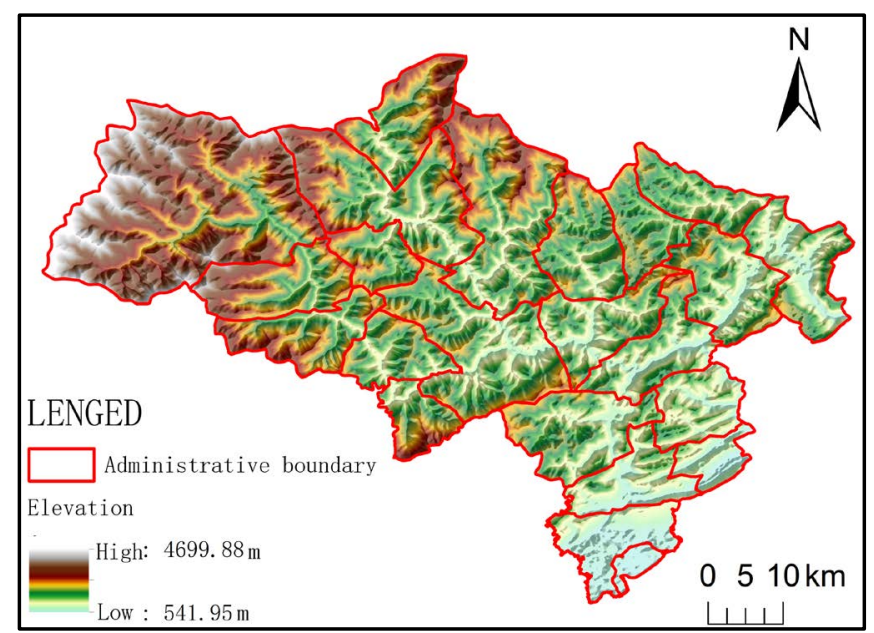

Figure 1. Introduction to the study area. 
Data Spatial Cloud (http://www.gscloud.cn/), which is obtained by mosaic, projection, and cropping; the vegetation coverage index (NDVI) was calculated from the multi-band remote sensing image of Beichuan County in 2019 by Landsat and obtained on ENVI; the water area ratio of each township was obtained by extracting the current land use data of Beichuan County in 2019; based on the meteorological data of Beichuan County for many years, the spatial interpolation method is used to obtain the grid data of annual mean precipitation in Beichuan County; by collecting the distribution of natural occurrence points in Beichuan County in recent 15 years and analysis of Nuclear Density using GIS10.2, the spatial distribution data of natural disaster risk in Beichuan County was obtained.

\subsection{Research Design}

By choosing for humans to live has a direct impact on natural factors, adopts the quantitative method to evaluate natural human environment adaptability and binding in Beichuan County. Early for the selection of natural evaluation factors are mainly concentrated in the topographic factors, ground cover and water resources distribution, and early research ignored the impact of natural disasters on human settlement environment. In this paper, according to the actual situation of the study area and the data of the study area, that selected $30 \times 30 \mathrm{~m}$ as the evaluation unit. At the same time, natural disaster risks are added to the three indicators of topography, vegetation coverage index, and hydrological index to jointly build a natural adaptability evaluation system for the human settlement environment of Beichuan County to more comprehensively express the spatial distribution of natural resources suitable for population development in Beichuan County Happening. The technical route is shown in Figure 2.

\subsection{Research Method}

By selecting topographic relief, vegetation coverage index, hydrological index

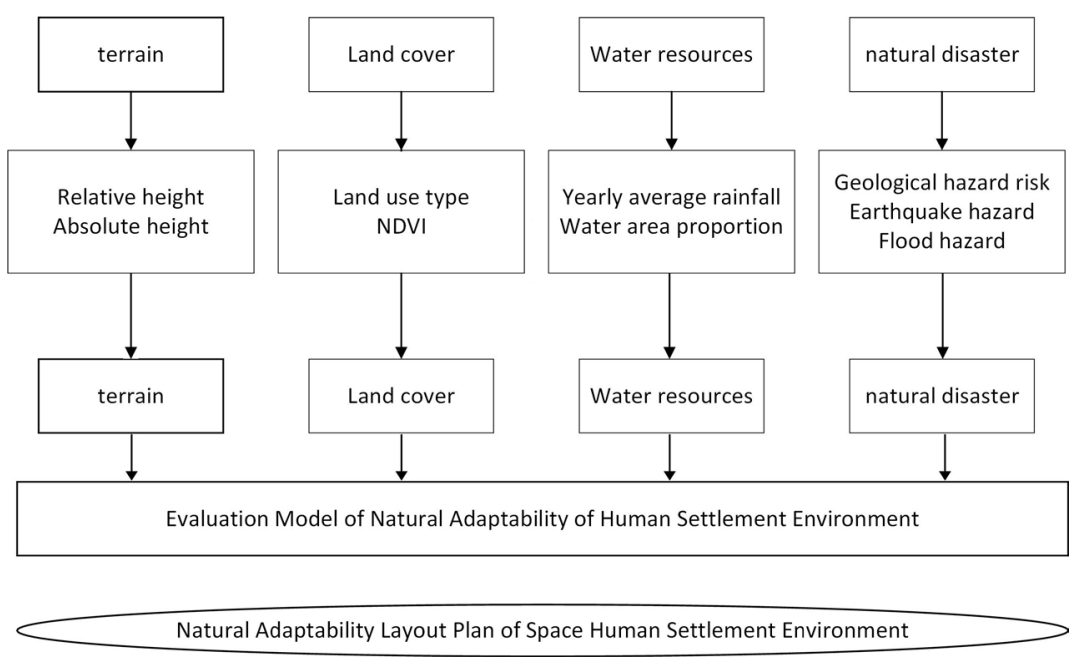

Figure 2. Flow chart of natural suitability evaluation of human settlement. 
and natural disaster risk to form the natural suitability evaluation system of human settlement environment in Beichuan County, it can provide the reference for revealing the spatial distribution of natural adaptability quality in Beichuan County and the construction of natural resource carrying capacity evaluation system.

\subsubsection{Relief of Topography (RDLS)}

The RDLS can reflect the suitability degree of topographic and geomorphic features in a small area for the human settlement environment. In this paper, $300 \times$ $300 \mathrm{~m}$ is taken as a small area unit, and measure the elevation difference in the unit and the product of the ratio of the elevation difference in the entire study area and the proportion of flat ground in the unit. The calculation formula is as follows:

$$
\operatorname{DRLS}=\{[\operatorname{Max}(\mathrm{h})-\operatorname{Min}(\mathrm{h})] /[\operatorname{Max}(\mathrm{h})-\operatorname{Min}(\mathrm{h})]\} \times[1-p(A) / A]
$$

In the equation: RDLS is the relief degree of the terrain; Max $(\mathrm{h})$ is the highest altitude of the region (m); Min (h) is the lowest altitude of the calculated region $(\mathrm{m})$; $\operatorname{Max}(\mathrm{h})$ is the highest altitude in the whole region (m); Min (h) is the lowest altitude in the whole region $(\mathrm{m}) ; p(A)$ is the flat area $(\leq 10 \mathrm{~m})$ within the region, $\mathrm{m}^{2} ; A$ is the total area, $\mathrm{m}^{2}$.

\subsubsection{Plant Coverage Index (NDVI)}

Vegetation coverage index can accurately reflect the coverage degree of surface vegetation in the study area, and the calculation formula is as follows:

$$
\mathrm{NDVI}=(\mathrm{NIR}-\mathrm{R}) /(\mathrm{NIR}+\mathrm{R})
$$

In the equation: NIR is the reflection value in the near-infrared band, $R$ is the reflection value in the red band.

\subsubsection{Hydrological Index (WCCI)}

The hydrological index can reflect the abundance of water resources in the study area. With reference to relevant research on regional water resources conditions, this article will reflect the abundance of water resources from two aspects. One is precipitation, which can reflect the water supply under natural conditions. The second is the area of the water area, which is mainly reflected in the strength of the water collection and storage capacity of the region, and the average annual precipitation and the proportion of the water area are assigned to characterize the size of the regional hydrological index. The calculation formula is as follows:

$$
\mathrm{WCCI}=\alpha P+\beta W a
$$

In the equation: WCCI is the hydrological index; $P$ is the normalized multi-year average precipitation, $W a$ is the normalized water area proportion, $\alpha$ and $\beta$ are the weights of $P$ and $W a$, with values of 0.2 and 0.8 .

\subsubsection{Natural Disaster Risk (NDR)}

Beichuan County is an area with frequent natural disasters, and its natural dis- 
aster risk reflects the possibility of regional natural disasters. Consider the actual situation in Beichuan County, the three main types of geological disasters, earthquake disasters, and flood disasters are used to characterize the risk of natural disasters.

$$
\mathrm{NDR}=W_{\text {DZZH }} \times \mathrm{DZZH}+W_{\text {EARTHAH }} \times \mathrm{EARTHAH}+W_{\mathrm{HLZH}} \times \mathrm{HLZH}
$$

In the equation: NDR is the risk of natural disasters; DZZH is the risk of geological disasters; EARTHAH is the risk of earthquake disasters; HLZH is the risk of flood disasters; $W_{\text {DZZH }}, W_{\text {EARTHAH }}$, and $W_{\text {HLZH }}$ are the weights of geological disasters, earthquake disasters, and flood disasters, respectively. Refer to related research materials and literature (Min et al., 2012), the weights are determined as $0.6,0.1$, and 0.3 respectively.

In the process of processing and standardizing these four types of main indicators, it is necessary to standardize the positive and negative indicators.

For positive indicators: The standardized processing formulas for multi-year average rainfall, water area proportion and vegetation coverage index are as follows:

$$
X=\left(X_{i}-X_{\min }\right) /\left(X_{\max }-X_{\min }\right)
$$

For negative indicators: The standardized processing formulas of topographic relief, geological hazard risk and flood hazard risk are as follows:

$$
X=1-\left(X_{i}-X_{\min }\right) /\left(X_{\max }-X_{\min }\right)
$$

\subsubsection{Construction of Natural Suitability Model of Habitat Environment Index (HEI)}

Based on individual indicators such as topographic suitability, vegetation coverage index, hydrological index, and natural disaster risk, a comprehensive evaluation model for the natural suitability of the human settlement environment-Habitat Environment Index (HEI) model is constructed to quantitatively calculate the population of Beichuan County. The calculation formula is as follows:

$$
\mathrm{HEI}=W_{\mathrm{NRDLS}} \times \mathrm{NRDLS}+W_{\mathrm{NDVI}} \times \mathrm{NDVI}+W_{\mathrm{NWCCI}} \times \mathrm{NWCCI}+W_{\mathrm{NDR}} \times \mathrm{NDR}
$$

In the equation: HEI is the human settlement environment index; NRDLS is the standardized terrain relief; NDVI is the standardized vegetation index; NWCCI is the standardized hydrological index; NDR is the standardized natural disaster risk index; $W_{\text {NRDLS }}, W_{\text {NDVI }}, W_{\text {NWCCI }}, W_{\text {NDR }}$ are the topographic relief, vegetation coverage index, hydrological index and natural disaster risk degree, and the weight values of each individual factor are $0.29,0.13,0.22,0.36$, respectively.

\section{Single-Element Evaluation of Natural Suitability of Human Settlement Environment in Beichuan County}

\subsection{Evaluation of Topographic Relief in Beichuan County}

After extracting the reverse standardized topographic undulation data of Beichuan County in GIS 10.2, see Figure 3(a). The purple part indicates that the 


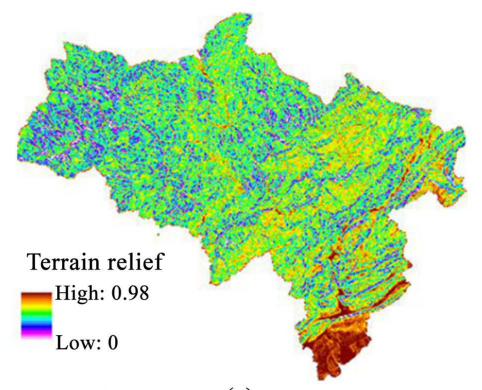

(a)

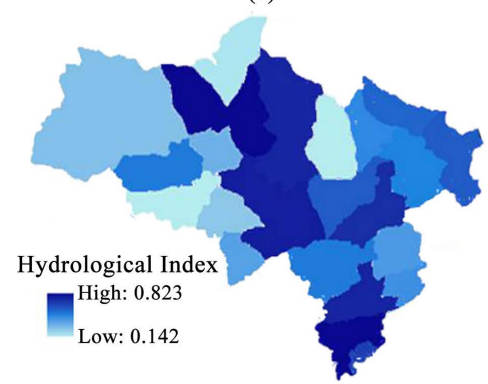

(c)

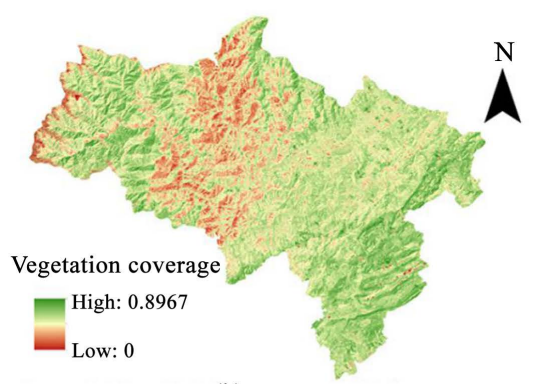

(b)

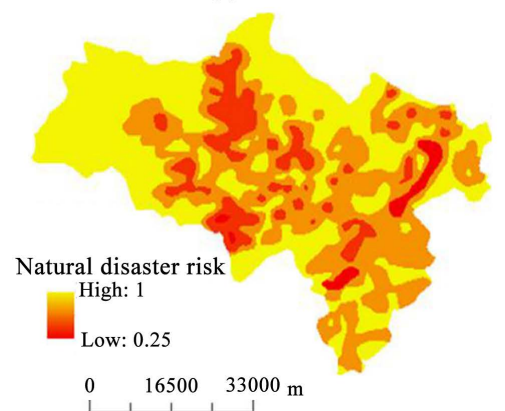

(d)

Figure 3. Standardized terrain relief, vegetation index, hydrological index, and natural disaster risk.

topographic relief is large. This area is mainly distributed in the west, which means that the region is not suitable for topography and geomorphology. The areas with low undulations for human gathering and development are mainly located in the southeast and near rivers. Townships with high populations such as New Beichuan County, Anchang Town, and Yong'an Town are located in this area.

\subsection{Evaluation of Vegetation Coverage Index in Beichuan County}

As shown in Figure 3(b), the calculation result of Beichuan County's vegetation coverage index shows that the highest value of Beichuan County's vegetation index reaches 0.89 , which is close to the highest level in the country (the highest value in the country is 1 ). The coverage conditions of Beichuan County are quite different and fragmented. The vegetation index is higher in the east, and the high-altitude areas such as the west show lower vegetation coverage due to more grassland.

\subsection{Evaluation of Hydrological Index in Beichuan County}

Figure 3(c) shows that the hydrological conditions in Beichuan County are relatively good, with the highest hydrological index being 0.823 , which is in the upper-middle level of the national hydrological index. In terms of spatial distribution, the hydrological conditions of Beichuan County's human settlements have obvious regional differences. The overall distribution is characterized by abundant water resources in the central and eastern regions, and lack of water resources in the western regions. 


\subsection{Evaluation of Natural Disaster Risk in Beichuan County}

After spatial data analysis, standardized geological disasters, earthquake disasters and flood disasters are obtained, thereby constructing the spatial pattern of natural disaster risk in Beichuan County, as shown in Figure 3(d). Because it is the data after reverse processing, the red part is indicating that the risk of natural disasters is high and it is not suitable for human living. The orange part means that the risk is low, and the limiting factors for the risk of natural disasters in this area are low. From the perspective of the spatial pattern, the areas of Guixi, Chenjiaba and Oldbeichuan located on the fault zone have high natural disaster risks, and the Piankou, Xiaoba and Kaiping areas have high natural disaster risks.

\section{Analysis of Spatial Pattern of Natural Suitability of Human Settlement Environment in Beichuan County}

This paper is supported by GIS spatial analysis technology, based on DEM, multi-band remote sensing images, and basic spatial data such as annual average rainfall, geological disasters, earthquake disasters and flood disasters, to construct Topographic relief (RDLS), Vegetation coverage index (NDVI), Natural disaster risk (NDR) and Hydrological index (WCCI) 4 index data, according to the Habitat environment index (HEI) calculation formula, the Beichuan County human settlement environment natural index is obtained, the value is between 19.72 - 85.25, where the higher the index, The better the quality of human settlements. Through the natural breakpoint method, the habitat environment index of the study area is divided into highly suitable areas, more suitable areas, general suitable areas, critical fitness suitable areas and unsuitable areas. The classification system is shown in Table 1.

\subsection{Highly Suitable Area}

The natural suitability of the human settlement environment and the index of highly suitable areas are between $68.70-85.25$. This area is not restricted by

Table 1. Classification system of natural suitability evaluation of human settlement environment in Beichuan.

\begin{tabular}{ccl}
\hline \multirow{2}{*}{ Laval } & \multicolumn{2}{c}{ Natural Suitability Index of Human Settlement Environment } \\
\cline { 2 - 3 } Highly suitable area & $68.70-85.25$ & $\begin{array}{l}\text { Basically not restricted by natural factors, most suitable } \\
\text { for human life and habitation }\end{array}$ \\
More suitable area & $61.95-68.70$ & $\begin{array}{l}\text { Natural factors are less restrictive, more suitable for } \\
\text { human life and habitation }\end{array}$ \\
General suitable area & $55.64-61.95$ & $\begin{array}{l}\text { There are certain natural restrictions, generally suitable } \\
\text { for human life and habitation }\end{array}$ \\
Critical fitness area & $48.02-55.64$ & $\begin{array}{l}\text { Natural factors are more restrictive and generally } \\
\text { suitable for human life and habitation } \\
\text { Unsuitable area }\end{array}$ \\
\hline $19.72-48.02$ & $\begin{array}{l}\text { Limited by multiple natural factors, barely suitable } \\
\text { for human habitation }\end{array}$ \\
\hline
\end{tabular}


natural conditions such as topography and natural disasters. It is the most suitable area for human living in the study area; the study area is highly suitable for an area of $427.68 \mathrm{~km}^{2}$, accounting for $14.06 \%$ of the area, it is mainly distributed in the southeast region. This area belongs to the border of Chengdu Plain, with flat terrain and abundant water resources. From the perspective of administrative divisions, it mainly includes Yongchang Town, Anchang Town, and Yong'an Town.

\subsection{More Suitable Area}

The natural suitability of the human settlement environment is relatively suitable. The index is between $61.95-68.70$ and the area is $892.41 \mathrm{~km}^{2}$, accounting for $29.34 \%$ of the entire study area; this type of area is less restricted and restricted by natural conditions such as topography, ground cover, and natural disasters. The natural environment is more suitable for human life and habitation. The more suitable areas are distributed more scattered, mainly located in the area around Anchang River in Beichuan and the surrounding areas of highly suitable areas. The latter area can be used as urban expansion land to meet the needs of urban expansion. From the perspective of administrative divisions, Leigu Town, Yuli Town and Duba Township are more suitable for human living.

\subsection{General Suitable Area}

The natural suitability index of the human settlement environment is generally between 55.64 - 61.95. This area is restricted to a certain extent by natural conditions such as terrain, ground cover, and natural disasters. The natural environment is generally suitable for human life and habitation. Its area is $924.84 \mathrm{~km}^{2}$, which accounts for $30.40 \%$ of the entire study area. The general suitable area has the largest area among all the natural suitable grades.

\subsection{Critical Fitness Area}

The natural suitability of the human settlement environment critical suitability index is between 48.02 - 55.64. Subject to the restrictions and constraints of terrain, ground cover, and natural disasters, the natural suitability of the human settlement environment is poor, and it is barely suitable for human life and housing. The critically suitable area for human settlements in Beichuan County is $543.68 \mathrm{~km}^{2}$, accounting for $17.87 \%$ of the study area. Through comparative analysis with natural disasters, it is found that these areas are mainly distributed around the two fault zones. They are areas with more severe earthquake disasters. The ecological environment is very fragile and therefore unsuitable for large populations. In terms of administrative divisions, the critically suitable areas are mainly distributed in Baishiqiang Tibetan Township, Manchao Township and Badi Township.

\subsection{Unsuitable Area}

The index of natural unsuitability of human settlement environment is 19.72 - 


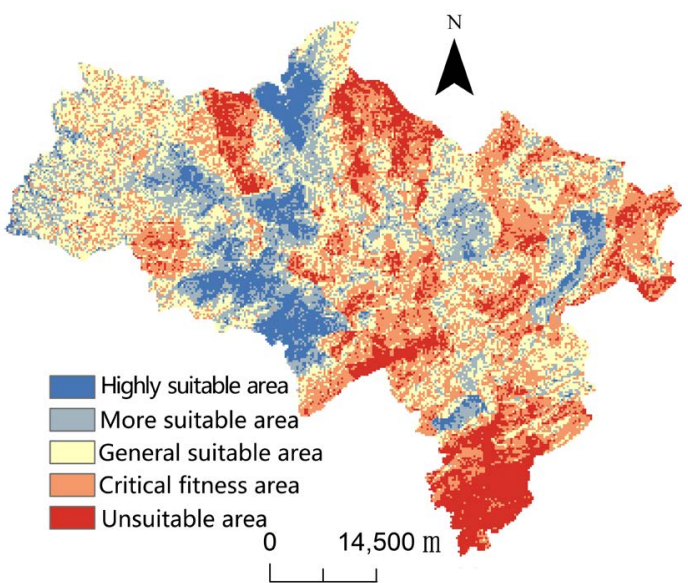

Figure 4. Spatial pattern of natural suitability of human settlement environment in Beichuan County.

48.02, which is seriously affected by topography, vegetation, hydrology, natural disasters and other factors, and is not suitable for human living and living (Figure 4). This type of area covers an area of about $253.17 \mathrm{~km}^{2}$, accounting for $8.32 \%$ of the total area. It is mainly distributed on the Xiaoba Qiang and Tibetan Township Fault Zone, Pankou Township, Guixi Township and Chenjiaba Township Fault Zone, with high and steep mountains, serious geological disasters and prominent unsuitability of ecological environment.

\section{Discussion and Conclusions}

\subsection{Discussion}

Natural human environment suitability evaluation is an important part of regional national spatial planning, it is also the foundation of human survival and development. Beichuan County is the worst-hit area of the 5.12 Wenchuan earthquake, the terrain of the complexity of the natural conditions limit the Beichuan County area the development of the overall quality. As a result, the evaluation of the natural suitability of the human settlement environment has important practical significance for the site selection and planning of the population, industry, resources and other spatial layouts of the people's residential areas in Beichuan County. Reasonable and efficient development and use of local resources is an inevitable way for the sustainable development of Beichuan County.

\subsection{Conclusions}

1) The areas with small fluctuation are mainly located in the southeast and near rivers. The towns with high population, such as Anchang Town and Yong'an Town and NewBeichuan County, are located in this region. In Beichuan County, the regional differences in land cover conditions are great. The vegetation coverage index in the eastern region is higher with a high degree of fragmentation, while the vegetation coverage in the western and other high-altitude regions is lower due to more grassland. 
2) In terms of spatial distribution, the hydrological conditions of the human settlement environment in Beichuan County have obvious regional differences, and the overall distribution is rich in water resources in the central and eastern part, while the western part is short of water resources. From the perspective of spatial pattern, the areas of Guixi, Chenjiaba, and Old Beichuan located on the fault zone have a high risk of natural disasters, while it is high in Pakou Xiaoba and Kaiping regions.

3) In the spatial pattern of natural suitability of human settlement environment in Beichuan County, the general suitable area with the overall index is between 19.72 - 85.25. General suitable area is the widest, accounting for $30.4 \%$ of the total area of Beichuan County; more suitable area ranked second, accounting for $29.33 \%$; critical suitable area accounted for $17.87 \%$; the area of suitable height area accounted for $14.06 \%$, and the area of unsuitable area accounted for $8.32 \%$.

\section{Conflicts of Interest}

The author declares no conflicts of interest regarding the publication of this paper.

\section{References}

Ayinur, M., Wahav, K., \& Guligna, H. (2012). Human Settlement Environment Suitability Evaluation in Southern Xinjiang Based on GIS. Arid Zone Resources and Environment, 26, 11-17.

Feng, Z. M., Yang, Y. Z., \& Yan, H. M. (2017). Research on the Carrying Capacity of Resources and Environment in the Past 100 Years: From Theory to Practice. Resources Science, 39, 379-395.

Ma, R. F., Zhang, W. Z., \& Yu, J. H. (2014). Review and Prospect of Human Settlement Environment Research in Chinese Geography. Geographical Science, 34, 1470-1479.

Mao, Q. Z. (2019). Theory and Practice of Chinese Human Settlement Environment Science. International Urban Planning, 34, 54-63. https://doi.org/10.22217/upi.2019.198

Min, J., Liu, C. X., \& Li, Y. C. (2012). The Natural Suitability of the Human Settlement Environment in Wanzhou District Based on GIS Technology. Resources and Environment in the Yangtze River Basin, 21, 1006-1012.

Wang, F., An, L. Z., \& Dang, A. R. (2020). Human-Land Coupling and Sustainable Human Settlement Environment in the Yellow River Basin. Geographical Research, 39, 1707-1724.

Xu, M. J., \& Yang, Z. S. (2016). Evaluation of Resource and Environmental Carrying Capacity and Analysis of Coordinated Development in Southwest Mountainous Areas: Taking Dehong Prefecture of Yunnan Province as an Example. Journal of Natural Resources, 31, 1726-1738.

Yang, X. Z., \& Wang, Q. (2013). Environmental Quality Assessment and Impact Analysis of Rural Human Settlements in the Tourist Area of Southern Anhui. Acta Geographica Sinica, 68, 851-867.

Zhang, L., Liu, J. F., \& Zou, W. H. (2012). Research on Infrared Small-Scale Detection Method of Urban Human Settlement Ecology. Infrared, 33, 38-44. 
Zhao, D. S., Guo, C. Y., \& Zheng, D. (2019). Research Progress in Ecological Carrying Capacity. Acta Ecologica Sinica, 39, 399-410.

Zhu, B. Y., Li, G. Z., \& Liu, C. Y. (2013). Evaluation of the Natural Suitability of Human Settlements in Jilin Province Based on RS and GIS. Remote Sensing for Land and Resources, 25, 138-142. 